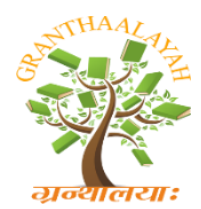
INTERNATIONAL JOURNAL OF RESEARCH
GRANTHAALAYAH
A knowledge Repository

Science

\title{
A MODIFICATION OF AN ESTIMATION METHOD OF THE NATURAL FREQUENCY OF A CUBE FORM MICRO SATELLITE
}

\author{
Kei-Ichi Okuyama *1, Shigeru Hibino ${ }^{1}$, Misuzu Matsuoka ${ }^{1}$, Sidi A. Bendoukha ${ }^{1}$, \\ Aleksander Lidtke ${ }^{1}$ \\ ${ }^{1}$ Applied Sciences and Integrated System Engineering, Kyushu Institute of Technology, 1-1 \\ Sensui-cho, Tobata Ward, Kitakyushu, Fukuoka Prefecture 804-0015, Japan
}

\begin{abstract}
Micro satellites must survive severe mechanical conditions during their launch phase. One design requirement for rockets is the stiffness requirement, i.e. the natural frequencies requirement. In the early stages of satellite development, presumption of the natural frequency of a satellite may be difficult.

The material used for the structure of many micro satellites is an aluminum alloy. The structure subsystem occupies a large portion of the satellite mass, and the elastic modulus of this aluminum alloy is larger than that of other subsystems. Therefore, the mechanical property of the aluminum alloy cannot be used to represent the mechanical property of the whole satellite. The density of an actual satellite differs from the density of the aluminum alloy. Therefore, when estimating the minimum natural frequency, the size and the elastic modules of an actual satellite structure must be used. When using an actual satellite structure, the estimated minimum natural frequencies of the lateral direction and the longitudinal direction during the ascent phase are in agreement with the measured values acquired by the vibration tests.

In order to shorten a process of satellite development, this paper describes a practical method for estimating the natural frequency of a cube-shaped micro satellite

This paper is a modified version of the previous paper [1] using new measurement results.
\end{abstract}

Keywords: Micro Satellite; Natural Frequency; Stiffness Requirement; Structure Designing; Structure Development.

Cite This Article: Kei-Ichi Okuyama, Shigeru Hibino, Misuzu Matsuoka, Sidi A. Bendoukha, and Aleksander Lidtke. (2018). "A MODIFICATION OF AN ESTIMATION METHOD OF THE NATURAL FREQUENCY OF A CUBE FORM MICRO SATELLITE.” International Journal of Research - Granthaalayah, 6(7), 121-131. 10.29121/granthaalayah.v6.i7.2018.1290.

\section{Introduction}

When a spacecraft such as a probe, which explores a planet or the sun, or a satellite which goes the around the earth, is launched with a rocket, they are exposed to severe mechanical conditions. Launch environments consist of a series of events, each of which has several independent sources 
of load for a probe and a satellite. Some loads are relatively steady-state; or constant over time, such as thrust while a rocket engine burns. Some are transient, such as thrust when a rocket ignites or shuts down. Acoustic loads are sound pressure waves. Because most acoustics include waves with many different frequencies, they cause structures to vibrate randomly. Pyrotechnic shock, or pyro shock for short, is high-intensity, high-frequency vibration caused by the explosives commonly used to separate stages.

One of the types of spacecraft is a small satellite, and they are differentiated by mass. Small satellites which are $100 \mathrm{~kg}$ or less, $10 \mathrm{~kg}$ or less, and $1 \mathrm{~kg}$ or less are called a micro satellite, nanosatellite, and picosatellite, respectively. In this paper, all of these three satellites are treated as a micro satellite.

Since these micro satellites must survive these severe mechanical conditions, the design requirements of the rocket are the strength requirement and the stiffness requirement. Significant stresses are generated on a micro satellite structure according to the static loads and the dynamic loads during the ascent phase. These stresses must not deviate from the allowable yield strength or the ultimate strength of the structure materials. The margin of safety (MS) is defined as the ratio between the allowable yield strength, or the ultimate strength, and the actual stresses multiplied by a safety factor minus one. This means that the value of the MS must be greater than or equal to zero. Furthermore, we have to satisfy a rocket requirement of the natural frequencies for a satellite. When using an H-IIA rocket which is a Japanese key rocket, the natural frequencies in the longitudinal direction and in the lateral direction must be larger than $100 \mathrm{~Hz}$ and $50 \mathrm{~Hz}$ respectively [2].

Usually, micro satellite design is performed through a procedure which designs and manufactures a bread board model, an engineering model. These models used for evaluation have satisfied the strength requirement and the stiffness requirement by using a vibration test. The design of these models is performed by CAD and the internal stress analysis and the natural frequency analysis of a micro satellite structure during the ascent phase are conducted in a finite-element-method analysis. In an early stage of development, which has a finite-element-method model of a satellite in the process of creation, presumption of the natural frequency of a satellite may be difficult. In order to shorten the process of satellite development, this paper describes a practical estimation method of the natural frequency of a cube form micro satellite.

This paper is a modified version of the previous paper [1] using new measurement results.

\section{Prediction of Minimum Natural Frequency of the Previous Paper}

A satellite by which the fitting was carried out in a rocket is expressed in Fig. 1 [3]. This is called a single-degree-of-freedom system, i.e. a SDOF system. This SDOF system is loaded by the force $F_{0} \sin \omega t$ at the mass $m$, were $\omega$ is the angular frequency and $t$ is time.

The mass is suspended by a linear spring with a spring stiffness $k$ and a damper with a damping constant $c$. 
The equation of motion of the SDOF system is:

$m \ddot{x}+c \dot{x}+k x=F_{0} \sin \omega t$

Where $x(t), \dot{x}(t), \ddot{x}(t)$ which represent displacement, velocity and acceleration.

The general solution of Eq. 1 is defined by the following equation:

$$
\begin{gathered}
x=e^{-\zeta \omega_{n} t}\left(C_{1} \sin \omega_{d} t+C_{2} \cos \omega_{d} t\right) \\
+\frac{\left(F_{0} / k\right) \omega_{n^{2}}}{\left(\omega_{n^{2}}-\omega^{2}\right)^{2}+\left(2 \zeta \omega_{n} \omega\right)^{2}}\left[\left(\omega_{n^{2}}-\omega^{2}\right) \sin \omega t-2 \zeta \omega_{n} \omega \cos \omega t\right] .
\end{gathered}
$$

$C_{1}$ and $C_{2}$ of Eq. 2 are constants decided based on an initial condition. For example, when the initial displacement is $x(t)=0$, the initial velocity $\dot{x}(t)=0$, the constants $C_{1}$ and $C_{2}$ are:

$$
\begin{aligned}
& C_{1}=\frac{\left(F_{0} / k\right) \omega_{n^{2}}}{\left(\omega_{n^{2}}-\omega^{2}\right)^{2}+\left(2 \zeta \omega_{n} \omega\right)^{2}} \frac{\omega}{\omega_{d}}\left(\omega^{2}-\omega_{d^{2}}+\zeta^{2} \omega_{n^{2}}\right) \\
& C_{2}=\frac{\left(F_{0} / k\right) \omega_{n^{2}}}{\left(\omega_{n^{2}}-\omega^{2}\right)^{2}+\left(2 \zeta \omega_{n} \omega\right)^{2}} \frac{\omega}{\omega_{d}} 2 \zeta \omega_{n} \omega_{d} .
\end{aligned}
$$

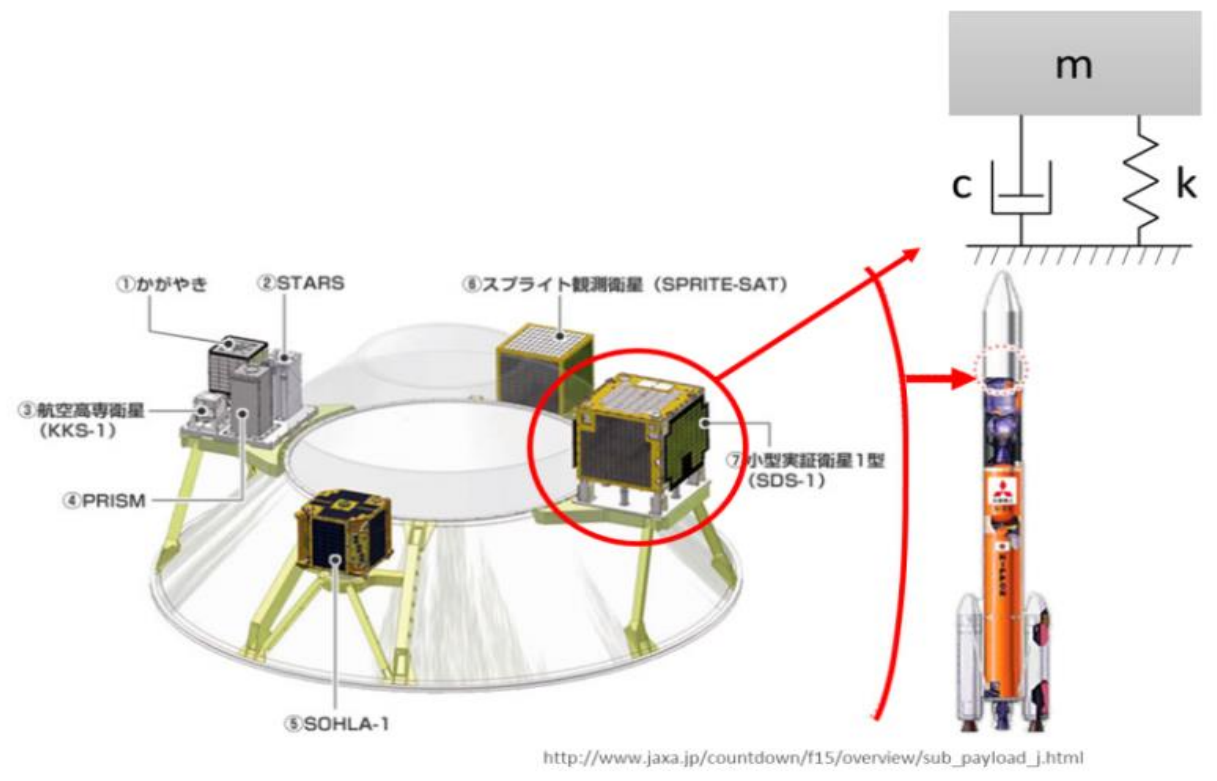

Figure 1: micro satellites in an H-IIA rocket and a Single-Degree-Of-Freedom system

The natural angular frequency of a non-damping system, the natural angular frequency of a damping system and the damping ratio are $\omega_{n}, \omega_{d}$ and $\zeta$ respectively. Thus $\omega_{n}, \omega_{d}$ and $\zeta$ are expressed as:

$\omega_{n}=\sqrt{k / m}, \omega_{d}=\sqrt{1-\zeta^{2}} \omega_{n}, \zeta=c / 2 \sqrt{m k}$. 
Since the natural angular frequency $\omega$ can be indicated as $\omega=2 \pi f$ using the natural frequency $f, f_{n}$ and $f_{d}$ are expressed as:

$f_{n}=\frac{1}{2 \pi} \sqrt{\frac{k}{m}}, f_{d}=\frac{1}{2 \pi} \sqrt{1-\zeta^{2}} f_{n}$

The form of the micro satellites which are used in this paper take the form of a cube; which is expressed as a rod, as shown in Fig. 2. This is a cantilever beam, the upper end of the rod is free to deflect but the lower end is rigidly clamped.

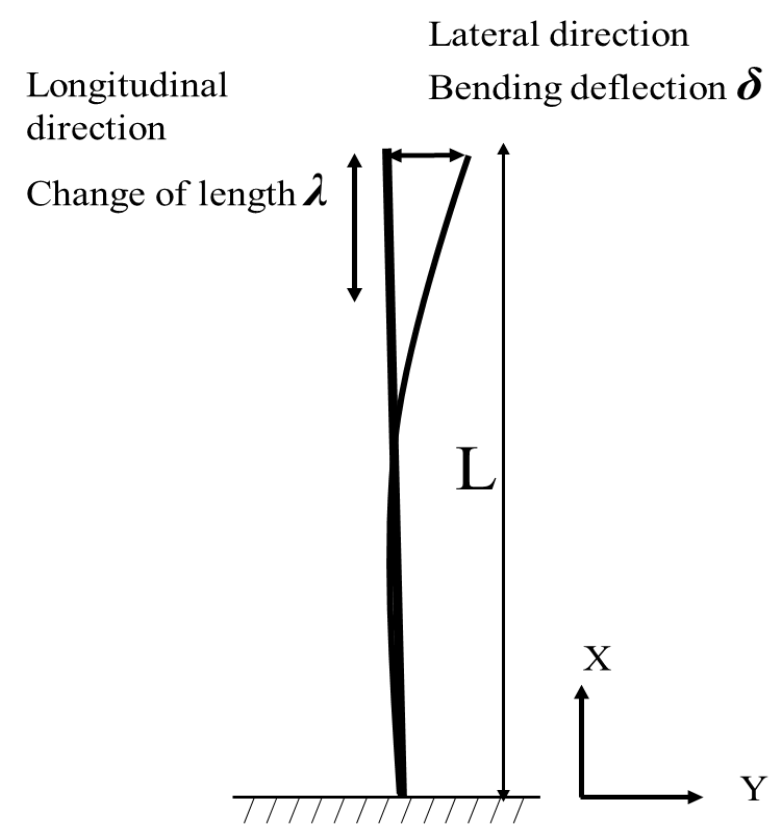

Figure 2: Rod from which length changes in longitudinal direction (x-direction) and lateral direction ( $y$-direction)

In the development of micro satellites, the value of $\zeta$ being used is 0.05 or below its value [4-7]. Therefore, the damping natural frequency $f_{d}$ is almost the same as the non-damping natural frequency $f_{n}$. There are some approximate solutions of a non-damping vibration of a onedimensional distribution mass system.

A force $P$ applies to this rod in $x$-direction. The rod has a cross-section $A$ and a length $L$. The elongation of the rod, due to the applied force $P$, is denoted with $\lambda$. The stiffness of the rod $k$ is defined with:

$k=P / \lambda$

The total strain $\varepsilon$ is:

$\varepsilon=\lambda / L$ 
The strain $\varepsilon$ is the ratio between the occurring stress $\sigma$ and the elastic modulus $E$ by Hooke's Law as:

$\varepsilon=\sigma / E=P / A E$

Thus the elongation $\lambda$ of the rod now becomes,

$\lambda=\varepsilon L=P L / A E$,

and therefore the stiffness $k$ is shown as:

$k=A E / L$

The minimum natural frequency of $x$-direction, which is the longitudinal direction of the launching phase $f_{n \text {, longitudinal }}$ can be estimated with

$f_{n, \text { longitudinal }}=\frac{1}{2 \pi} \sqrt{\frac{k}{m}}=\frac{1}{2 \pi} \sqrt{\frac{A E}{m L}}=\frac{1}{2 \pi} \sqrt{\frac{A E}{\rho A L^{2}}}=\frac{1}{2 \pi L} \sqrt{\frac{E}{\rho}}$.

When a load acts on this rod with the bending moment $M_{0}$ in $y$-direction; displacement $y(x)$ is expressed by:

$\frac{d^{2} y}{d x^{2}}=\frac{M_{0}}{E I}$

The displacement $y(x)$ is expressed by integrating Eq. 13:

$y(x)=\frac{M_{0}}{E I} \frac{1}{2} x^{2}+C_{1} x+C_{2}$

Since the displacement and the deflection angle at the fixed end (at $x=0$ ) are each zero, $C_{1}=C_{2}=0$. Since the maximum deflection occurs at the free end $(x=L)$ :

$y_{\max }=(y)_{x=L}=\frac{M_{0}}{2 E I} L^{2}$.

The stiffness $k$ is defined with Eq. 16:

$k=\frac{F}{y_{\max }}=\frac{m g}{m g L^{3} / 2 E I}=\frac{2 E I}{L^{3}}$

Where the bending moment $M_{0}$ is the value obtained by multiplying the length $L$ from the fixed end to the free end and the force $F$ which is $m g$, the gravitational acceleration is $g$. 
Therefore, the minimum natural frequency can be calculated with:

$f_{n}=\frac{1}{2 \pi} \sqrt{\frac{k}{m}}=\frac{1}{2 \pi} \sqrt{\frac{2 E I}{m L^{3}}}$.

Because the satellite form that is dealt with in this paper is a cube which has a length of one side is $L$, the moment of inertia of area $I$ can be calculated by:

$I=\frac{L^{4}}{12}$

Thus the minimum natural frequency of the $y$-direction, which is the lateral direction $f_{n \text {,lateral }}$ can be estimated using Eq. 19:

$f_{n, \text { lateral }}=\frac{1}{2 \pi} \sqrt{\frac{2 E I}{m L^{3}}}=\frac{1}{2 \pi} \sqrt{\frac{2 E L^{4}}{12 \rho A L^{4}}}=\frac{1}{2 \pi L} \sqrt{\frac{1}{6} \frac{E}{\rho}}$.

The structure material used for many micro satellites is an aluminum alloy. The structure subsystem occupies a substantial portion of the entire satellite mass; the elastic modulus of this aluminum alloy is larger than that of other subsystems. Therefore, the mechanical property of the main structure material cannot be used to represent the mechanical property of the whole satellite. The density $\rho_{m}$ of a material which mainly constitutes the satellite differs from the actual density of the satellite $\rho_{s}$. A length of one side of a cube-shaped satellite, namely specific length $L_{s}$, is expressed by:

$L_{s}=\left[\left(\rho_{s} / \rho_{m}\right) V_{s}\right]^{1 / 3}$

Where $V_{s}$ is the actual satellite density.

From the elastic modulus of other subsystems being very small compared with the elastic modulus of structure material $E_{m}$, the elastic modulus of an actual satellite $E_{s}$ is indicated by Eq. 21 ,

$E_{s}=E_{m}\left[\left(\rho_{s} / \rho_{m}\right)\right]$

Therefore, Eq. 12 and Eq. 19 can be rewritten as:

$f_{n, \text { longitudinal }}=\frac{1}{2 \pi L_{S}} \sqrt{\frac{E_{S}}{\rho_{S}}}$

$f_{n, l a t e r a l}=\frac{0.408}{2 \pi L_{S}} \sqrt{\frac{E_{S}}{\rho_{S}}}$

Using Eq. 15 and Eq. 27, the minimum natural frequency of the lateral direction is expressed as:

$f_{n, \text { lateral }}=0.408 f_{n, \text { longitudinal }}$ 


\section{Vibration Test}

\subsection{Test Facility}

In order to acquire the minimum natural frequencies of micro satellites, vibration tests were carried out. These vibration tests were mainly done in the center for nanosatellite testing (CeNT) [8] at the Kyushu Institute of Technology using a vibration testing facility which generates vibration according to the parameters such as arbitrary force, acceleration and frequency. The completeness of a satellite structure can be evaluated by arbitrary oscillating loads. The vibration testing equipment of the CeNT is the $35 \mathrm{kN}$ type of EMIC Corporation [9]. For this FH-35K/60 model, the maximum exciting force in a sine wave is $35,000 \mathrm{~N}$, the frequency range is up to $2,200 \mathrm{~Hz}$, the maximum acceleration $1,000 \mathrm{~m} / \mathrm{s} 2$ and the maximum payload mass is $400 \mathrm{~kg}$. The vibration test facility is illustrated in Figure 3.

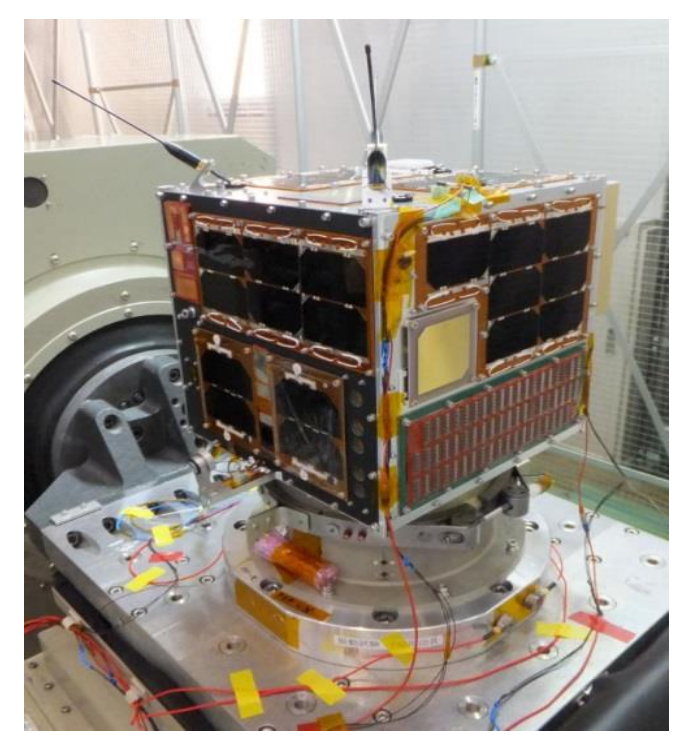

Figure 3: vibration testing facility at the center for nanosatellite testing (CeNT) at the Kyushu Institute of Technology

\subsection{Test Conditions and Specimens}

The vibration tests were carried out based on the standard ISO 17025. This ISO-17025 is a standard certified by an authoritative third-party accreditation body to determine whether laboratories / calibration laboratories have the ability to generate accurate measurement / calibration results. Testing laboratories that conduct product inspection, analysis, measurement, etc., require certification. Requirements for calibration organizations conducting the calibration work of measuring instruments are specified in this standard. Certified organizations must have management ability in product management / quality control and technology for generating reliable tests / calibration results. The authority of this standard is recognized internationally. There are two main fields of testing and calibration, and the CeNT is concerned with the test item "Vibration test based on ISO-19683 and JAXA JERG - 2 - 130 - HB 003 of artificial satellite and satellite components." The CeNT had already received certification. Each micro satellite was vibrated in the $\mathrm{X}$-direction and the $\mathrm{Y}$-direction, and the minimum natural frequencies for each were measured. 
The specifications of the micro satellites used for this testing are shown in Table 1. All the forms of the micro satellites with which the testing was provided are all cubes; the masses range from approximately $720 \mathrm{~g}$ up to $65 \mathrm{~kg}$. Those forms were cubes mostly and the lengths of one side ranged from approximately $10 \mathrm{~cm}$ to $50 \mathrm{~cm}$. The main material of these satellite structures is an aluminum alloy, the ratio of the satellites densities to this aluminum alloy density were from approximately 0.41 to 0.13 .

Table 1: Specifications of the micro satellites used for this testing

\begin{tabular}{|c|c|c|c|c|c|c|c|c|c|c|}
\hline \multicolumn{3}{|c|}{\begin{tabular}{|l} 
Satellite structure \\
\end{tabular}} & \multicolumn{8}{|c|}{ Satellite structure specifications } \\
\hline \multirow{3}{*}{$\begin{array}{c}\text { Main } \\
\text { material }\end{array}$} & \multirow{2}{*}{$\begin{array}{c}\text { Density } \\
\rho_{\mathrm{m}}\end{array}$} & \multirow{2}{*}{$\begin{array}{c}\begin{array}{c}\text { Modulus } \\
\text { of } \\
\text { elasticity }\end{array} \\
E\end{array}$} & \multicolumn{3}{|c|}{ Size } & \multirow{2}{*}{$\begin{array}{c}\text { Volume } \\
\mathbf{V}_{\mathrm{s}}\end{array}$} & \multirow{2}{*}{$\begin{array}{r}\text { Mass } \\
\text { m }\end{array}$} & \multirow{2}{*}{$\begin{array}{c}\text { Density } \\
\rho_{\mathrm{s}}\end{array}$} & \multirow{2}{*}{$\begin{array}{c}\begin{array}{c}\text { Density } \\
\text { ratio }\end{array} \\
\rho_{\mathrm{s}} / \rho_{\mathrm{m}}\end{array}$} & \multirow{2}{*}{$\begin{array}{c}\begin{array}{c}\text { Specific } \\
\text { length } L_{s}\end{array} \\
\left(\left(\rho_{\mathrm{s}} / \rho_{\mathrm{m}}\right) V_{\mathrm{s}}\right)^{1 / 3}\end{array}$} \\
\hline & & & $\mathbf{W}$ & D & $\mathbf{H}$ & & & & & \\
\hline & {$\left[\mathrm{kg} / \mathrm{m}^{3}\right]$} & [GPa] & {$[\mathrm{mm}]$} & {$[\mathrm{mm}]$} & {$[\mathrm{mm}]$} & {$\left[\mathbf{m}^{3}\right]$} & {$[\mathrm{kg}]$} & {$\left[\mathrm{kg} / \mathrm{m}^{3}\right]$} & {$[-]$} & [m] \\
\hline \multirow{13}{*}{$\begin{array}{l}\text { Aluminum } \\
\text { alloy }\end{array}$} & \multirow[t]{13}{*}{2770} & \multirow[t]{13}{*}{72} & 0.10 & 0.10 & 0.11 & $\begin{array}{l}1.14 \mathrm{E}- \\
03\end{array}$ & 0.723 & 637 & 0.230 & 0.064 \\
\hline & & & 0.10 & 0.10 & 0.11 & $\begin{array}{l}1.10 \mathrm{E}- \\
03\end{array}$ & 1.10 & 969 & 0.350 & 0.074 \\
\hline & & & 0.10 & 0.10 & 0.11 & $\begin{array}{l}1.14 \mathrm{E}- \\
03\end{array}$ & 1.13 & 996 & 0.359 & 0.074 \\
\hline & & & 0.10 & 0.10 & 0.11 & $\begin{array}{l}1.10 \mathrm{E}- \\
03\end{array}$ & 1.28 & 1130 & 0.408 & 0.077 \\
\hline & & & 0.39 & 0.39 & 0.42 & $\begin{array}{l}6.21 \mathrm{E}- \\
02\end{array}$ & 21.7 & 349 & 0.126 & 0.199 \\
\hline & & & 0.50 & 0.50 & 0.49 & $\begin{array}{l}1.24 \mathrm{E}- \\
01\end{array}$ & 43.9 & 355 & 0.128 & 0.251 \\
\hline & & & 0.50 & 0.50 & 0.50 & $\begin{array}{l}1.25 \mathrm{E}- \\
01\end{array}$ & 45.7 & 366 & 0.132 & 0.255 \\
\hline & & & 0.49 & 0.50 & 0.52 & $\begin{array}{l}1.27 \mathrm{E}- \\
01\end{array}$ & 46.9 & 367 & 0.132 & 0.257 \\
\hline & & & 0.45 & 0.45 & 0.54 & $\begin{array}{l}1.09 \mathrm{E}- \\
01\end{array}$ & 50.8 & 455 & 0.164 & 0.264 \\
\hline & & & 0.50 & 0.50 & 0.50 & $\begin{array}{l}1.25 \mathrm{E}- \\
01\end{array}$ & 55.0 & 440 & 0.159 & 0.271 \\
\hline & & & 0.50 & 0.50 & 0.55 & $\begin{array}{l}1.38 \mathrm{E}- \\
01\end{array}$ & 57.6 & 419 & 0.151 & 0.275 \\
\hline & & & 0.50 & 0.52 & 0.52 & $\begin{array}{l}1.35 \mathrm{E}- \\
01\end{array}$ & 60.0 & 434 & 0.157 & 0.279 \\
\hline & & & 0.50 & 0.50 & 0.70 & $\begin{array}{l}1.75 \mathrm{E}- \\
01\end{array}$ & 64.8 & 370 & 0.134 & 0.286 \\
\hline
\end{tabular}

\section{Test Results and Discussions}

The measurement results, and the calculation results which are computed used Eq.22 to Eq.24 are shown in Table 2, Fig. 2 and Fig. 3. Although the minimum natural frequencies of the satellites where the density ratio is small, i.e., the satellites whose mass are approximately $50 \mathrm{~kg}$ class, is around $200 \mathrm{~Hz}$. The minimum natural frequencies of the $1 \mathrm{~kg}$ class satellites are around $1,000 \mathrm{~Hz}$. The measured values and the calculated values of the both domain are not in agreement. It was 
found that the natural frequencies cannot be predicted using these equations. From the form of the all satellites treated by this research having been cubes, this means that the elastic modulus of an actual satellite $E_{s}$ cannot express by Eq. 21. All measurements results were statistically processed; the ratio to the elastic modulus of structure material $E_{m}$ of the elastic modulus of an actual satellite $E_{s}$ which is in agreement with measurement results was calculated. It is expressed as:

$E_{S}=0.0001502 e^{8.137\left(\rho_{s} / \rho_{m}\right)} E_{m}$

The natural frequencies which used and predicted Eq. 25 instead of Eq. 21 are shown in Fig. 6 and Figure 7.

The measured values and the calculated values of all domains where the density ratio are small were in agreement. We can understand that the calculated values of natural frequencies are good in agreement in measured values from Fig. 6 and Fig. 7. When we use Eq. 25 instead of Eq. 21, Eq. 22 and Eq. 23 are effective for simple prediction of the natural frequency of a micro satellite. Furthermore, in this study, the lateral external load was taken as the bending moment. The ratio of the natural frequency in the longitudinal direction and the natural frequency in the lateral direction under this condition is 0.408 times. Based on the results in Table 2, the lateral natural frequencies obtained by measurements are approximately 0.34 times the values in the longitudinal direction. When an external load other than the bending moment is applied, this ratio is 0.408 times or more. One of the external loads closest to 0.34 times is the bending moment.

Table 2: Comparison of minimum natural frequencies between vibration test results and simple estimated results

\begin{tabular}{|c|c|c|c|c|c|c|c|c|c|}
\hline \multirow{4}{*}{$\begin{array}{c}\begin{array}{c}\text { Satellite } \\
\text { main } \\
\text { structure }\end{array} \\
\begin{array}{c}\text { Main } \\
\text { material }\end{array}\end{array}$} & \multicolumn{4}{|c|}{$\begin{array}{l}\text { Satellite structure } \\
\text { specifications }\end{array}$} & \multicolumn{2}{|c|}{ Vibration test results } & \multicolumn{2}{|c|}{ Estimation results } & \multirow[t]{4}{*}{ Remarks } \\
\hline & \multicolumn{3}{|c|}{ Size } & \multirow{2}{*}{$\begin{array}{c}\text { Mass } \\
\mathbf{m}\end{array}$} & \multicolumn{2}{|c|}{$\begin{array}{l}\text { Minimum natural } \\
\text { frequency }\end{array}$} & \multicolumn{2}{|c|}{$\begin{array}{c}\text { Minimum natural } \\
\text { frequency }\end{array}$} & \\
\hline & $\mathbf{W}$ & $\mathbf{D}$ & $\mathbf{H}$ & & \begin{tabular}{|c|}
$\begin{array}{c}\text { longitudinal } \\
\text { direction }\end{array}$ \\
\end{tabular} & $\begin{array}{c}\text { lateral } \\
\text { direction }\end{array}$ & $\begin{array}{c}\text { longitudinal } \\
\text { direction }\end{array}$ & $\begin{array}{c}\text { lateral } \\
\text { direction }\end{array}$ & \\
\hline & {$[\mathrm{mm}]$} & {$[\mathrm{mm}]$} & {$[\mathrm{mm}]$} & [kg] & {$[\mathbf{H z}]$} & {$[\mathbf{H z}]$} & {$[\mathbf{H z}]$} & {$[\mathrm{Hz}]$} & \\
\hline \multirow{13}{*}{$\begin{array}{l}\text { Aluminum } \\
\text { alloy }\end{array}$} & 0.10 & 0.10 & 0.11 & 0.723 & 1390 & - & 12679 & 5176 & \\
\hline & 0.10 & 0.10 & 0.11 & 1.10 & 733 & - & 10968 & 4477 & \\
\hline & 0.10 & 0.10 & 0.11 & 1.13 & 860 & 560 & 10957 & 4472 & \\
\hline & 0.10 & 0.10 & 0.11 & 1.28 & 1247 & - & 10539 & 4302 & \\
\hline & 0.39 & 0.39 & 0.42 & 21.7 & 324 & 94 & 4078 & 1664 & \\
\hline & 0.50 & 0.50 & 0.49 & 43.9 & 207 & 63 & 3231 & 1319 & \\
\hline & 0.50 & 0.50 & 0.5 & 45.7 & 209 & 55 & 3180 & 1298 & \\
\hline & 0.49 & 0.50 & 0.52 & 46.9 & 120 & 41 & 3151 & 1286 & \\
\hline & 0.45 & 0.45 & 0.54 & 50.8 & 129 & 49 & 3071 & 1254 & \\
\hline & 0.50 & 0.50 & 0.5 & 55.0 & 166 & 50 & 2996 & 1223 & \\
\hline & 0.50 & 0.50 & 0.55 & 57.6 & 186 & 47 & 2948 & 1203 & \\
\hline & 0.50 & 0.52 & 0.52 & 60.0 & 170 & 53 & 2911 & 1188 & \\
\hline & 0.50 & 0.50 & 0.70 & 64.8 & 144 & 43 & 2842 & 1160 & \\
\hline
\end{tabular}




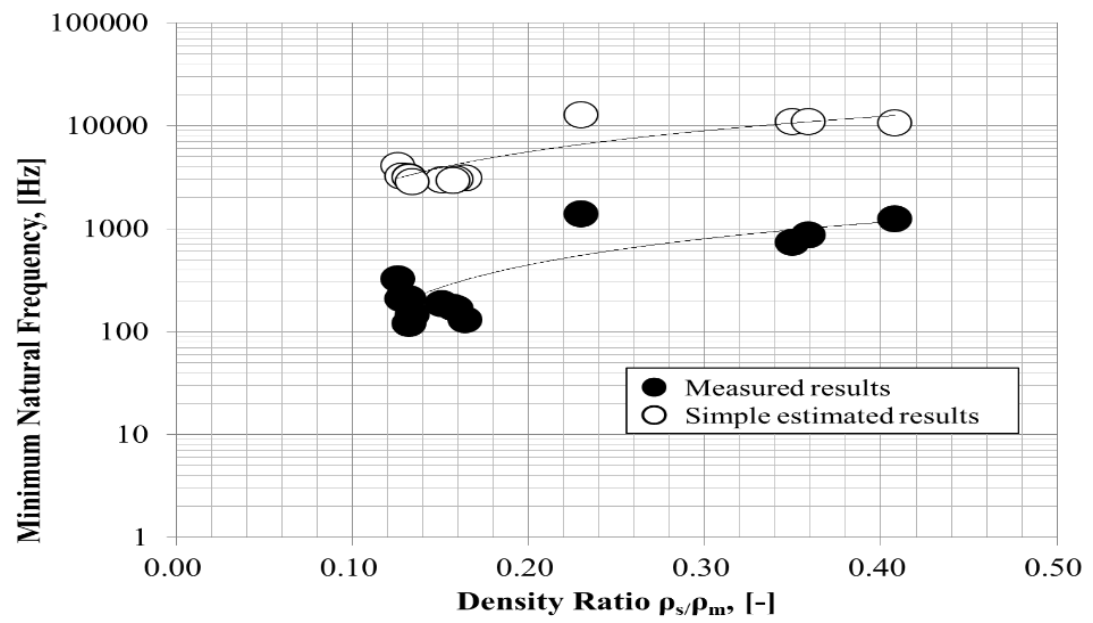

Figure 4: Comparison of minimum natural frequencies between vibration test results and simple estimated results predicted using Eq. 21 in longitudinal direction

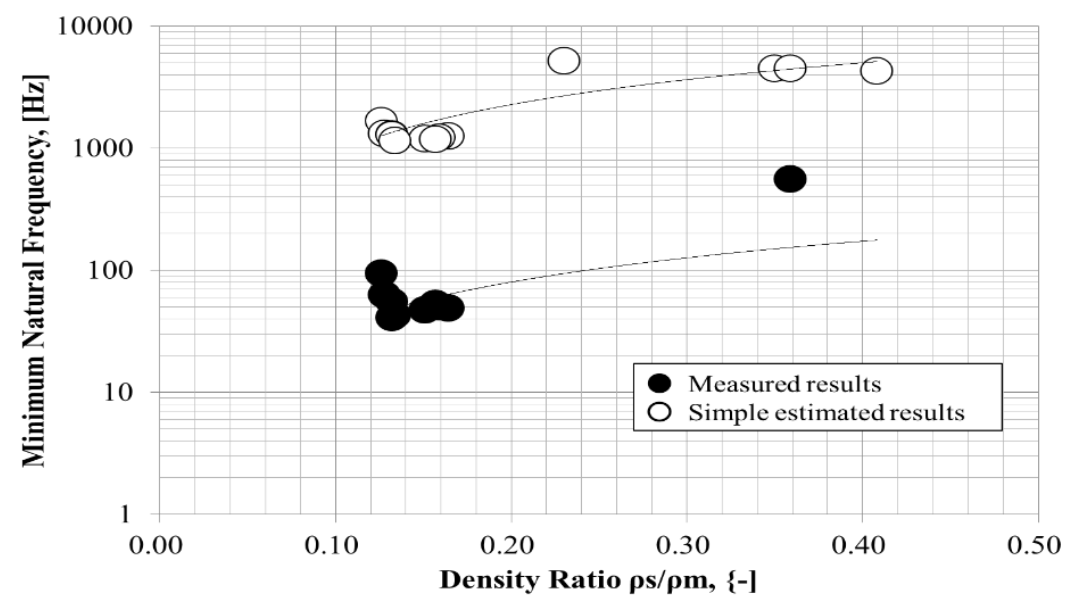

Figure 5: Comparison of minimum natural frequencies between vibration test results and simple estimated results predicted using Eq. 21 in lateral direction

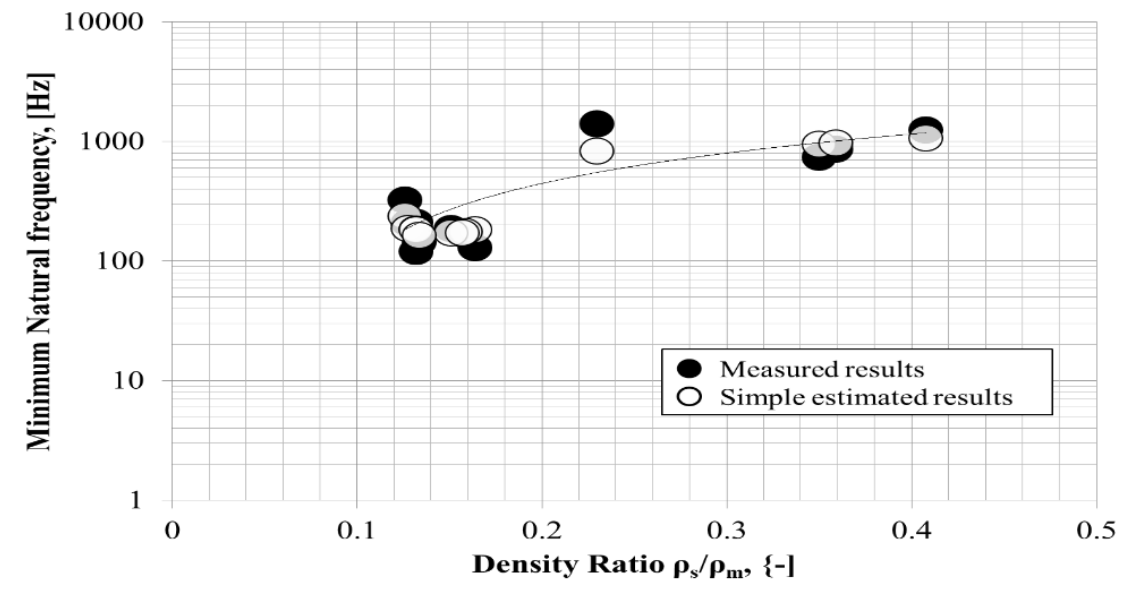

Figure 6: Comparison of minimum natural frequencies between vibration test results and simple estimated results predicted using Eq. 25 in longitudinal direction 


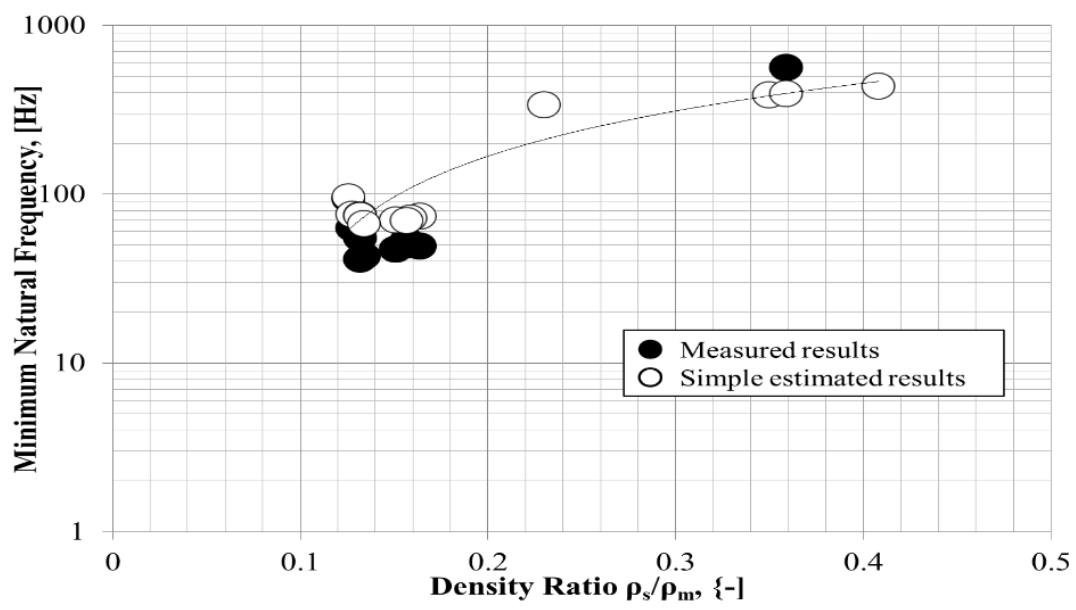

Figure 7: Comparison of minimum natural frequencies between vibration test results and simple estimated results predicted using Eq. 25 in lateral direction

\section{References}

[1] Kei-ichi Okuyama, Shigeru Hibino, Misuzu Matsuoka and Aleksander Lidtke, An Estimation Method of The Natural Frequency of A Cube Form Micro Satellite, Vol.6 (Iss.3) , pp. 88-97, March 2018, ISSN. 2394-3629(P) Doi.org/10.5281/zenodo.345434.

[2] Japan Aerospace Exploration Agency, User's manual of H-IIA rocket (in Japanese), JERG-4-011A, 2015.

[3] Mitsubishi Heavy Industries, Ltd., User's manual of H-IIA rocket, YET04001, Vol.4, 2015, Japan.

[4] Japan Aerospace Exploration Agency, Structural design standard (in Japanese), JERG-2-320A, 2011.

[5] M. J. Casiano, Extracting Damping Ratio from Dynamic Data and Numerical Solutions, NASA TM-2016-218227, 2016.

[6] L. E. Kinsler, A. R. Frey, A. B. Coppens and J. V. Sanders, Fundamentals of Acoustics, John Wiley \& Sons, 4th edition, 2000.

[7] J. JaapWijker, Spacecraft Structures, Springer, 2008 edition, 2008.

[8] Mengu CHO, Hirokazu MASUI, Yasuhiro AKAHOSHI, Koju HIRAKI, Minoru IWATA and Shinji HATTA, Initial Operations of Center for Nanosatellite Testing, 2nd Nano- Satellite Symposium, 14th-16th March, 2011, the University of Tokyo, Japan

[9] EMIC Corporation, User's manual of vibration testing system (Model FH-35K/60), 2018.

*Corresponding author.

E-mail address: okuyama@ ise.kyutech.ac.jp 